\title{
Application of Markowitz and Sharpe Models in Nepalese Stock Market
}

\author{
Rajan Bahadur Paudel \\ Sujan Koirala
}

\begin{abstract}
The purpose of this article is to test whether or not Markowitz and Sharpe models of portfolio selection offer better investment alternatives to Nepalese investors. It has been done by applying those models in a sample of 30 stocks traded in Nepalese stock market. The study finds that the application of these elementary models developed about a half century ago offer better options for making decision in the choice of optimal portfolios in Nepalese stock market.
\end{abstract}

Key words: portfolio, Nepalese Stock Markets, Markowitz and Sharpe model

A RATIONAL INVESTOR ALWAYS ATTEMPTS to minimize risk and maximize return on his investment. Investing in more than one security is a strategy to attain this often-conflicting goal. In 1952, Harry M. Markowitz developed a model that could be used to systematically operationalise the old adage - don't put all eggs in one basket. Markowitz's portfolio model is concerned with selecting optimal portfolio by risk adverse investors. According to the model risk adverse investors should select efficient portfolios, the portfolio that maximizes return at a given level of risk or minimize risk at a given level of return, which can be formed by combining securities having less than perfect positive correlations in their returns.

Markowitz model was theoretically elegant and conceptually sound. However, its serious limitation was the volume of work well beyond the capacity of all except a few analysts. To resolve the problem William F. Sharpe developed a simplified variant of the Markowitz model that reduces substantially its data and computational requirements (Sharpe 1963).

As per Sharpe's model, the construction of an optimal portfolio is simplified if a single number of measures the desirability of including a stock in the optimal portfolio. If we accept his model, such a number exists. In this case, the desirability of any stock is directly related to its excess return-to-beta ratio. If the stocks are ranked from highest to lowest order by excess return to beta that represents the desirability of any stock's inclusion in a portfolio. The number of stocks selected depends on a unique cutoff rate such that all stocks with higher ratios will be included and all stocks with lower ratios excluded.

The establishment and operation of the Nepal Stock Exchange (NEPSE) in 1994 has opened door to investors. Although it has evolved slowly, it still is characterized by small number of listed securities (150 securities of 142 companies) by the end of 2006, traditional trading practice (open-outcry system), dominance of one type of securities (banks) in the market portfolio, least trading of government securities, absence of professional investment advisors, very low level of information disclosure and trading driven by rumors than systematic analysis. Capital market, at present, is profitable to the investors who can overlook the rule of game. It is yet to be rational to a discerning investor. Unless it is changed, capital market will not contribute in a desirable way to contribute to growth (Koirala and Bajracharya 2004). This poses a great challenge for the rational investors of Nepal which indicate a need of systematic approach in investment decision.

Although the stock market of Nepal is in infant stage, all types of investors can benefit from the sound and in-depth knowledge of portfolio analysis which help them to diversify their investment risk. The systematic analysis of available portfolios and thereby selection of optimal portfolio help to diversify risk without adversely affecting the return. It also facilitates the mobilization of resources in 
Application of Markowitz and Sharpe Models in Nepalese Stock Market

all sector of the economy by inducing investors to invest in stocks of different industrial categories and thereby fosters the economy growth of the country.

The present study has been carried out with a view to apply portfolio models propounded by Markowitz and Sharpe in the Nepalese stock market and thereby assist selecting optimal portfolios out of the stocks listed in NEPSE. In other words the study answers this question: do Markowitz and Sharpe models improve investment performance of an investor in Nepalese stock market?

The study has considered only the common stock in forming the portfolios and has formed a limited number of two-asset portfolios under Markowitz model. Further, it has formed an optimal portfolio combining various stocks under Sharpe model. Evidently, this study has provided a number of options for making decision in the choice of optimal portfolios according to the need and preference of investors.

\section{Theoretical Framework}

\subsection{Harry M. Markowitz and Portfolio Selection Model}

Prior to Markowitz's work, investors focused on assessing the risks and rewards of individual securities in constructing their portfolios. Standard investment advice was to identify those securities that offered the best opportunities for gain with the least risk and then construct a portfolio from these. Following this advice, an investor might conclude that bank stocks all offered good risk-reward characteristics and compile a portfolio entirely from these. Intuitively, this would be foolish. Markowitz formalized this intuition. Markowitz began a revolution by suggesting that the value of a security to an investor might best be evaluated by its mean, its standard deviation and its correlation to other securities in the portfolio. This audacious suggestion amounted to ignoring a lot of information about the firm-its earnings, dividend policy, capital structure, market, and competitor-, and calculating a few simple statistics. Detailing a mathematic of diversification, he proposed that investors focus on selecting portfolios based on their overall risk-reward characteristics instead of merely compiling portfolios from securities that each individually has attractive risk reward characteristics. In a nutshell, investors should select portfolios not individual securities.

The Markowitz model is a single-period model, where an investor forms a portfolio at the beginning of the period. The investor's objective is to maximize the portfolio's expected return subject to an acceptable level of risk or minimize risk subject to an acceptable expected return. The assumption of a single time period, coupled with assumptions about the investor's attitude toward risk, allows risk to be measured by the variance or standard deviation of the portfolio's return. Thus, as indicated by the arrow in Fig. 1, the investor is trying as far to go northwest as possible.

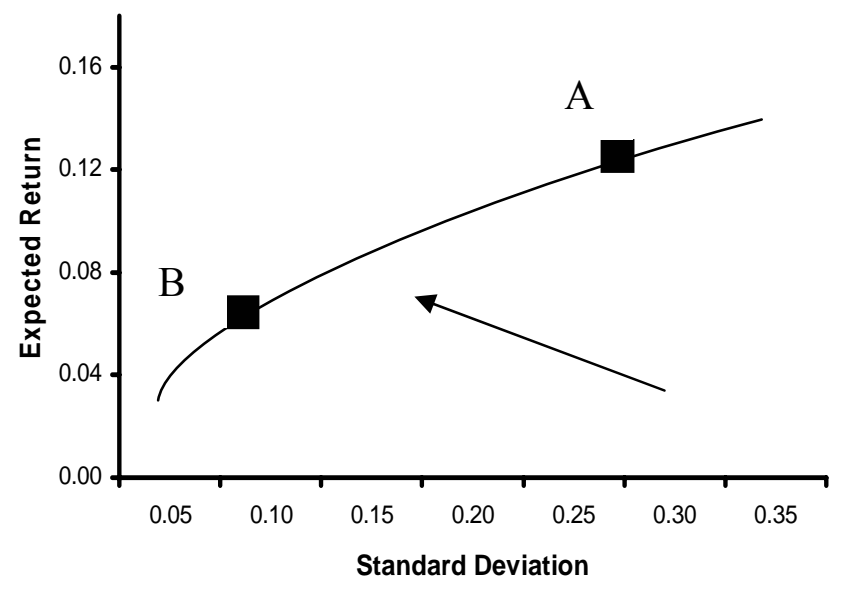

Fig. 1: Markowitz Portfolio Selection 
As securities are added to a portfolio, the expected return and standard deviation change in very specific ways, based on the way in which the added securities co-vary with the other securities in the portfolio. The best than an investor can do (i.e., the furthest northwest a portfolio can be) is bounded by a curve that is the upper half of a hyperbola, as shown in above figure. This curve is known as the efficient frontier. According to the Markowitz model, investors select portfolios along this curve, according to their tolerance for risk. An investor who can live with a lot of risk might choose portfolio A, while a more risk-averse investor would be more likely to choose portfolio B. One of the major insights of the Markowitz model is that it is a security's expected return, coupled with how it covaries with other securities, that determines how it is added to investor portfolios.

Markowitz's primary contribution consisted of developing a rigorously formulated, operational theory for portfolio selection under uncertainty. Due to the possibility of reducing the risk through diversification, the risk of the portfolio, measured as its variance, will depend not only on the individual variances of the return on different assets but also on the pair wise covariance of all assets. Hence, the essential aspect pertaining to the risk of an asset is not the risk of each asset in isolation but the contribution of each asset to the risk of the aggregate portfolio. However, the law of large numbers is not wholly applicable to the diversification of risks in portfolio choice because the returns on different assets are correlated in practice. Thus, in general, risk cannot be eliminated, regardless of how many types of securities represented in a portfolio.

\subsection{Markowitz Model: Mean Variance Portfolio Selection}

We can construct large number of portfolio by combining security and by varying proportion of investment among assets. Among the portfolios formed, some are efficient and many others are inefficient i.e. dominated. The sets of portfolios that (i.) offer maximum expected return for varying levels of risk, and (ii.) offer minimum risk for varying levels of expected return, are known as "efficient sets". The efficient portfolio lies along efficient frontier. Efficient frontier posses unique risk and return characteristics. The investor will choose portfolios from these efficient portfolios. This concept falls under the Modern Portfolio Theory. The theory assumes, among other things, that investors devotedly try to minimize risk while motivated for the highest return possible. The theory states that investors will act rationally always making decisions aimed at maximizing their return for their acceptable level of risk.

Harry M. Markowitz described this portfolio theory in 1952 and it shows that it is possible for different portfolios to have varying levels of risk and return. Each investor must decide how much risk they can handle and then allocate or diversify their investment according to this decision. The optimal-risk portfolio is usually determined to be somewhere in the middle of the curve because as one go higher up the curve, $\mathrm{s} /$ he takes on proportionately more risk for a lower incremental return. But low risk/low return portfolios are pointless because s/he can achieve a similar return by investing in risk-free returns like government securities.

Investors can choose how much volatility s/he is willing to bear in her/his portfolio by picking any other point that falls on the efficient frontier. This will give her/him maximum return for risk $\mathrm{s} / \mathrm{he}$ wishes to accept. To select a minimum variance portfolio, an investor should plot her/his indifference curves on the efficient set and then proceeds to choose the portfolio that is on the indifference curve that is farthest northeast. These portfolios will correspondence to the point at which an indifference curve is just tangent to the efficient set.

In Fig. 2, the point of tangency between indifference curve $\mathrm{IC}_{2}$ and efficient curve intercept at point $\mathrm{A}$. The point $\mathrm{A}$ is the optimal portfolio combination with the indifference curve $\mathrm{IC}_{2}$. Portfolio $\mathrm{A}$ is the feasible portfolio that represents the tangency point between efficient set and indifference curve of the investor. Although investor will prefer $\mathrm{IC}_{1}$ but not such portfolio exists. Here, portfolio $\mathrm{A}$ is the dominant portfolio set.

The Markowitz model was a brilliant innovation in the science of portfolio selection. With almost a disarming slight-of-hand, Markowitz showed us that all the information needed to choose the best portfolio for any given level of risk is contained in three simple statistics: mean, standard deviation and correlation. In short, Harry Markowitz fundamentally altered how investment decisions were made. Virtually every major portfolio manager today consults an optimization program. They may not 
follow its recommendation exactly, but they use it to evaluate basic risk and return trade-offs (Goetzmann 1995).

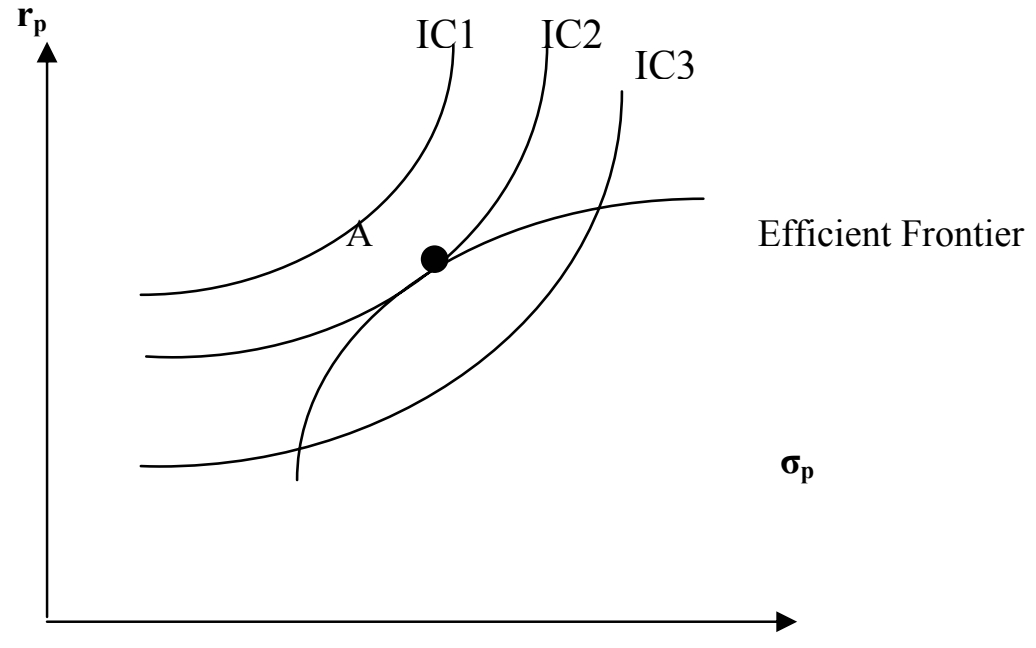

Fig.2: Efficient Frontier

Why doesn't everyone use the Markowitz model to solve his/her investment problem? The answer again lies in statistics. The historical mean return may be a poor estimate of the future mean return. As you increase the number of securities, you increase the number of correlations you must estimate and you must estimate them correctly to obtain the right answer. For large number of stocks, one is certain to find correlations that are widely inaccurate. Unfortunately, the model does not deal well with incorrect inputs. That is why it is best applied to allocation decisions across asset classes, for which the number of correlations is low, and the summary statistics are well estimated (Goetzmann 1995).

\subsection{Sharpe Model of Portfolio Optimization}

William Sharpe, who among others has tried to simplify the process of data inputs, data tabulation, and reaching a solution, has developed a simplified variant of the Markowitz model that reduces substantially its data and computational requirements. Markowitz model was theoretically elegant and conceptually sound. However, its serious limitation was the sophisticated and volume of work well beyond the capacity of all except a few analysis.

William F. Sharpe's pioneering achievement in this field was contained in his essay entitled to Capital Asset Prices: A Theory of Market Equilibrium under Conditions of Risk (Sharpe 1964). As per Sharpe model or Portfolio Optimization model, the linearity of security should be found. The beta of security represents the market linearity of the stock. The market influences each stock. Negative beta defines that security is not linear to the market. The security having negative beta coefficient is rejected as investment alternative. Similarly, security that provides lower rate of return than risk-free rate of return is rejected as investment alternative because such stocks entail some investment risk but they are not compensating the investment risk.

The construction of an optimal portfolio is simplified if a single number measures the desirability of including a stock in the optimal portfolio. If we accept the single-index model, such a number exists. In this case, the desirability of any stock is directly related to its excess return-to-beta ratio $\left(R_{j}\right.$ $\left.-R_{f}\right) / \beta_{i}$.

If the stocks are ranked by excess return to beta (from highest to lowest), the ranking represents the desirability of any stock's inclusion in a portfolio. The number of stocks selected depends on a unique cutoff rate such that all stocks with higher ratios of $\left(R_{i}-R_{f}\right) / \beta_{i}$ will be included and all stocks with lower ratios excluded. To determine which stocks are included in the optimum portfolio, the following steps are necessary: 
- Calculate the excess return-to-beta ratio for each stocks under review and the rank them from highest to lowest.

- The optimum portfolio consists of investing in all stocks for which $\left(R_{i}-R_{f}\right) / \beta_{i}$ is greater than a particular cutoff point $C^{*}$.

All securities whose excess return-to-beta ratios are above the cutoff rate are selected and all whose securities with the ratios below the cutoff rate are rejected. The value of $\mathrm{C}^{*}$ is computed from the characteristics of all securities that belong in the optimum portfolio. To determine $\mathrm{C}^{*}$ it is necessary to calculate its value as if different numbers of securities were in the optimum portfolio. For a portfolio of $i$ stocks, $C_{i}$ is given by:

$$
C_{i}=\frac{\sigma_{m}^{2} \sum_{i=1}^{i} \frac{\left(R_{i}-R_{f}\right) \beta_{i}}{\sigma_{e i}^{2}}}{1+\sigma_{m}^{2} \sum_{i=1}^{i} \frac{\beta_{i}^{2}}{\sigma_{e i}^{2}}}
$$

Where,

$\sigma_{\mathrm{m}}^{2}=$ variance in the market index

$\sigma^{2}{ }^{2}=$ variance of a stock's movement that is not associated with the movement of the market index; this is the stock's unsystematic risk

$\mathrm{R}_{\mathrm{i}}=\quad$ expected return of stock $i$

$\mathrm{R}_{\mathrm{f}}=$ risk-free rate of return

After getting the $C_{i}$ of each security, investors select highest $C_{i}$ value that is $C^{*}$ among all the securities and develop a ranking on all securities. Then investors compare $\mathrm{C}^{*}$ with excess return to beta of each security. Then, the securities having value greater than $\mathrm{C}^{*}$ are selected. Once investors know which securities are to be included in the optimum portfolio, investors must calculate the percent invested in each security. The percentage invested in each security is:

Weight of security $i\left(Z_{i}\right)=\frac{Z_{i}}{\sum_{i=1}^{N} Z_{i}}$

Where,

$$
Z_{i}=\frac{\beta_{i}}{\sigma_{e i}^{2}}\left(\frac{R_{i}-R_{f}}{\beta_{i}}-C^{*}\right)
$$

Where.

$$
\begin{aligned}
& \mathrm{C}^{*}=\text { cutoff rate } \\
& \mathrm{R}_{\mathrm{i}}=\text { expected return of stock } i \\
& \mathrm{R}_{\mathrm{f}}=\text { risk-free rate of return } \\
& \beta_{\mathrm{i}}=\text { beta of stock } i \\
& \sigma_{\mathrm{ei}}=\quad \text { unsystematic risk of stock } i
\end{aligned}
$$

The above expression determines the relative investment in each security. The first expression simply scales the weights on each security so that they sum to 1 (ensure full investment). The residual variance on each security $\sigma_{\mathrm{e}}$ plays an important role in determining how much to invest in each security. Then the portfolio return can be obtained by using following equation:

$\mathrm{R}_{\mathrm{p}}=W_{1} R_{1}+W_{2} R_{2}+\quad \ldots \ldots \ldots \ldots+W_{n} R_{n}$
Portfolio Variance $\left(\sigma_{p}^{2}\right)=\left[\left(\sum_{i=1}^{n} W_{i} \beta_{i}\right)^{2} \sigma_{m}^{2}\right]+\left[\left(\sum_{i=1}^{n} W_{i} e_{i}^{2}\right)\right]$

Where,

$\mathrm{W}_{\mathrm{i}}=$ weight/proportion of investment in security $i$ 
Application of Markowitz and Sharpe Models in Nepalese Stock Market

$\beta_{\mathrm{i}}=$ beta of stock $i$

$\sigma_{\mathrm{i}}=$ standard deviation of stock $i$

$\mathrm{e}_{\mathrm{i}}=$ unsystematic risk of security $i$ Sharpe model.

By following the above-mentioned procedure, the optimum portfolio can be obtained under

\section{Review of Studies in Nepalese Stock Market}

There are a few studies, mostly Master degree dissetation (Bhatta 1995, Sapkota 1999, Adhikari 2002, Joshi 2002, Poudyal 2002, Shrestha 2004, Shrestha A. 2004, Pantha 2005, Khadaka 2006 and Koirala 2006), on the topic. These studies have attempted to form optimum portfolios but have number of limitations including, unrealistic assumptions, small number of samples, samples being drawn from only one industry, very short study period, etc.

\section{The Sample and the Method of Analysis}

The study is based on the risk and return data of a sample of 30 stocks listed in NEPSE (refer to Annex 1). The selection of sample is based on the following criteria:

- Since the study covers a period of FY 1997/98 to Mid-May 2006, only those companies whose common stocks were listed before the FY 1996/97 are selected as sample companies.

- Only the stocks offering mean return above the risk-free rate are selected as samples. The securities that provide lower return than the risk-free rate of return are excluded because such stocks entail some investment risk but they are not compensating the investment risk (Sharpe 1956).

Samples selected on the above criteria cover six out of eight industrial categories and constitutes 23.25 percent of the total stock listed in NEPSE at the end of FY 1996/97. The number of total listed companies and number of sample stocks in each industrial category are given in Table1.

Table1: Representation of Sample Stocks

\begin{tabular}{lccc}
\hline Industry & Sample Companies & No. of Listed Companies & Proportion \\
\hline Commercial Bank & 7 & 15 & $46.67 \%$ \\
Development Banks & 0 & 7 & 0.00 \\
Finance Companies & 12 & 47 & 25.53 \\
Insurance Companies & 6 & 14 & 42.86 \\
Manufacturing \& Processing & 3 & 29 & 10.34 \\
Hotels & 1 & 4 & 25.00 \\
Trading & 1 & 8 & 12.50 \\
Others & 0 & 5 & 0.00 \\
\hline Total & 30 & 129 &
\end{tabular}

The data for the study have been collected from the publications and home pages of NEPSE, Nepal Securities Board and Nepal Rastra Bank. The following procedures have been followed to apply Markowitz's two-stock portfolio model.

- Mean return, standard deviation, beta of each stock and the market has been calculated based on past 10 years' (1997/98 to Mid-May 2006) return.

- Four hundred thirty-five two-stock portfolios have been formed from 30 sample stocks and correlations of these 435 sets have been calculated. 
- Out of the 435 sets, 50 sets of two-stock portfolios with least correlation have been selected for consideration.

- Risk minimizing weights, portfolios return and portfolio standard deviations have been calculated for 50 sets of two-stock portfolio.

- An efficient frontier has been developed on the basis of mean and standard of each portfolio.

The following procedures have been followed to apply Sharpe's model.

- Excess return-to-beta ratio has been calculated for each stock under review and they have been ranked from highest to lowest.

- A cutoff point has been determined.

- Optimum portfolio has been formed from those stocks that have higher excess return-to-beta ratio than the cutoff point.

\section{Analysis and Discussion}

\subsection{Return and Risk of Individual Securities and the Market}

The mean return and risk in terms of standard deviation, coefficient of variation (CV) and beta, have been calculated for 30 sample stocks and presented in Table 2. Among 30 sample companies, the stock of AFCL offers the highest average return ( 82.34 percent) followed by the stock of EBL (62.72 percent) and NBBL's stock (47.66 percent). Similarly, the stock of BBCL offers the lowest risk (15.55 percent) followed by the stock of YFL (20.35 percent) and BNBL (25.34 percent). In term of $\mathrm{CV}$ the stock of YFL has the lowest risk per unit of return followed by stock of SCBNL (0.88) and stock of CIT (0.92). In terms of systematic risk, the stock of AFCL has the highest beta (4.193) and the stock of BBCL has the lowest beta (0.235). Thus, among all 30 companies, the stock of AFCL is the best in terms of average return while the stock of BBCL is the best in terms of beta and the stock of YFL is best in terms of risk per unit of return (CV). Industry-wise comparison reveals that banks are the clear winner in terms of return as well as risk. The average market return for the period is 12.86 percent with 28.80 percent standard deviation.

Table 2: Mean Return, Standard Deviation, CV and Beta of Sample Stock and the Market

\begin{tabular}{|c|l|c|c|c|c|}
\hline S.N. & Banks & Mean Return (\%) & Standard Deviation (\%) & CV & Beta \\
\hline 1 & NABIL & 44.86 & 50.44 & 1.12 & 1.588 \\
\hline 2 & NIBL & 23.25 & 41.93 & 1.80 & 1.175 \\
\hline 3 & SCBNL & 32.37 & 28.44 & 0.88 & 0.919 \\
\hline 4 & HBL & 42.04 & 47.28 & 1.12 & 1.055 \\
\hline 5 & NSBIBL & 27.86 & 64.75 & 2.32 & 2.008 \\
\hline 6 & NBBL & 47.66 & 118.45 & 2.49 & 2.868 \\
\hline 7 & EBL & 62.72 & 72.74 & 1.16 & 2.046 \\
\hline & Sample banks & $\mathbf{4 0 . 1 1}$ & $\mathbf{5 5 . 9 4}$ & $\mathbf{1 . 3 9}$ & \\
\hline 8 & NFSCL & 41.92 & 140.36 & 3.35 & 3.216 \\
\hline 9 & NCML & 43.00 & 108.02 & 2.51 & 3.059 \\
\hline 10 & NFCL & 14.63 & 27.76 & 1.90 & 0.469 \\
\hline 11 & NSMFL & 30.26 & 108.98 & 3.60 & 2.865 \\
\hline 12 & AFCL & 82.34 & 163.78 & 1.99 & 4.193 \\
\hline 13 & KFL & 27.09 & 70.09 & 2.59 & 1.498 \\
\hline 14 & PFL & 18.49 & 55.07 & 2.98 & 1.514 \\
\hline 15 & CIT & 36.89 & 33.98 & 0.92 & 0.791 \\
\hline 16 & NFL & 39.41 & 79.66 & 2.02 & 1.825 \\
\hline 17 & AcFL & 30.42 & 45.36 & 1.49 & 1.295 \\
\hline 18 & YFL & 25.90 & 20.35 & 0.79 & 0.298 \\
\hline
\end{tabular}


Application of Markowitz and Sharpe Models in Nepalese Stock Market

Table 2: (Continued)

\begin{tabular}{|c|l|c|c|c|c|}
\hline 19 & SFL & 21.59 & 56.04 & 2.60 & 1.397 \\
\hline & $\begin{array}{l}\text { Sample finance } \\
\text { companies }\end{array}$ & $\mathbf{3 4 . 3 3}$ & $\mathbf{7 1 . 0 3}$ & $\mathbf{2 . 0 7}$ & \\
\hline 20 & NICL & 25.05 & 35.60 & 1.42 & 0.603 \\
\hline 21 & NLGICL & 18.03 & 35.93 & 1.99 & 0.937 \\
\hline 22 & HGICL & 16.27 & 49.89 & 3.07 & 1.315 \\
\hline 23 & UICL & 15.16 & 36.63 & 2.42 & 1.056 \\
\hline 24 & PICL & 15.71 & 36.13 & 2.30 & 0.833 \\
\hline 25 & EICL & 29.45 & 59.97 & 2.04 & 0.963 \\
\hline & $\begin{array}{l}\text { Sample } \\
\text { insurance } \\
\text { companies }\end{array}$ & $\mathbf{1 9 . 9 5}$ & $\mathbf{3 5 . 2 4}$ & $\mathbf{1 . 7 7}$ & \\
\hline 26 & BNBL & 8.18 & 25.34 & 3.10 & 0.291 \\
\hline 27 & BNTL & 29.08 & 63.11 & 2.17 & 1.461 \\
\hline 28 & UNL & 40.85 & 69.18 & 1.69 & 1.340 \\
\hline & $\begin{array}{l}\text { Sample mfg. } \\
\text { companies }\end{array}$ & $\mathbf{2 6 . 0 4}$ & $\mathbf{4 3 . 8 7}$ & $\mathbf{1 . 6 8}$ & \\
\hline 29 & SHL & 5.43 & 29.90 & 5.50 & 0.785 \\
\hline 30 & BBCL & 6.93 & 15.55 & 2.24 & 0.235 \\
\hline & $\begin{array}{l}\text { Sample other } \\
\text { companies }\end{array}$ & $\mathbf{6 . 1 8}$ & $\mathbf{1 5 . 8 7}$ & $\mathbf{2 . 5 7}$ & \\
\hline & Market return & 12.86 & 28.80 & 2.24 & \\
\hline
\end{tabular}

\subsection{Selection of Stocks for Two-stock Portfolio}

Application of Markowitz model suggests the formation of portfolios of stocks that have less than perfect positive correlation. For that matter correlations have been calculated for all possible sets (435 sets) that can be formed from the samples. The calculated correlation coefficients appear in Annex 2 and the summary of correlation is presented in Table 3.

Table 3: Summary of Correlation between 435 Pairs of Two-stocks

\begin{tabular}{|l|r|l|}
\hline \multicolumn{1}{|c|}{ Correlation (p) ranges } & \multicolumn{1}{c|}{ Pairs } & \multicolumn{1}{c|}{ Remarks } \\
\hline 0.80 to 1.00 & 146 & Highest: AFCL and NFSCL $(\rho=0.977)$ \\
\hline 0.60 to 0.799 & 151 & \\
\hline 0.40 to 0.599 & 69 & \\
\hline 0.20 to 0.399 & 34 & \\
\hline 0.00 to 0.199 & 17 & \\
\hline less than 0.00 & 18 & Lowest: $B B C L$ and $N F C L(\rho=0.437)$ \\
\hline
\end{tabular}

Among 435 pairs, there are 146 pairs having correlation coefficient (between 0.80 and 1.00 . Similarly, there are 151 pairs having correlation between 0.60 and 0.799 and remaining 120 pairs have correlation coefficient between 0.00 and 0.599 . There are only 18 pairs having negative correlation coefficient. The correlation between AFCL's stock and NFSCL's stock (0.977) is the highest among the stocks of sample companies followed by HGICL and NCML (0.974) and NFSCL and KFL (0.974). Similarly, correlation between BBCL and NFCL (-0.437) is the lowest followed by BBCL and NICL (-0.310) and BBCL and KFL (-0.240) (Annex 2). Among these 435 feasible sets, a set of 50 portfolios having least correlation coefficients has been selected for the study. The list of these portfolios appears in Annex 3 


\subsection{Calculation of Weights, Expected Return and Standard Deviation of 50 Portfolios}

Applying Markowitz's minimum variance portfolio formula, the weight of each stock included in 50 portfolios has been calculated which is presented in Annex 4. The expected return and standard deviation of all 50 sets of two-stock portfolios have also been computed (Annex 4). The expected return of the portfolios ranges between 6.57 percent to 45.65 percent whereas portfolio risk (standard deviation) ranges between 10.42 percent to 66.35 percent. Among 50 portfolio, Set-28, i.e., combination of stocks of AFCL (11.6 percent investment) and UNL (88.4 percent investment) provides highest return (45.65 percent) followed by Set-40, i.e., combination of NCML ( 22.4 percent investment) and UNL (77.6 percent investment) with 41.33 percent return and Set-26, i.e., combination of NFSCL (16.8 percent investment) and UNL stocks (83.2 percent investment) with 41.03 percent return. On the contrary, Set-1, i.e., the combination of NFCL (31 percent investment) and BBCL (69 percent investment) provides lowest risk (with standard deviation of return of 10.42 percent) followed by Set-2, i.e., the combination of NICL (22.3 percent investment) and BBCL (77.7 percent investment) with standard deviation of return of 12.23 percent and Set-9, i.e., the combination of BNBL (29.4 percent investment) and BBCL (70.6 percent investment) with the standard deviation of return of 12.55 percent.

\subsection{Identification of Efficient Sets}

The study has developed an efficient frontier using the expected return and standard deviation of fifty feasible sets which has been presented in Figure 1.

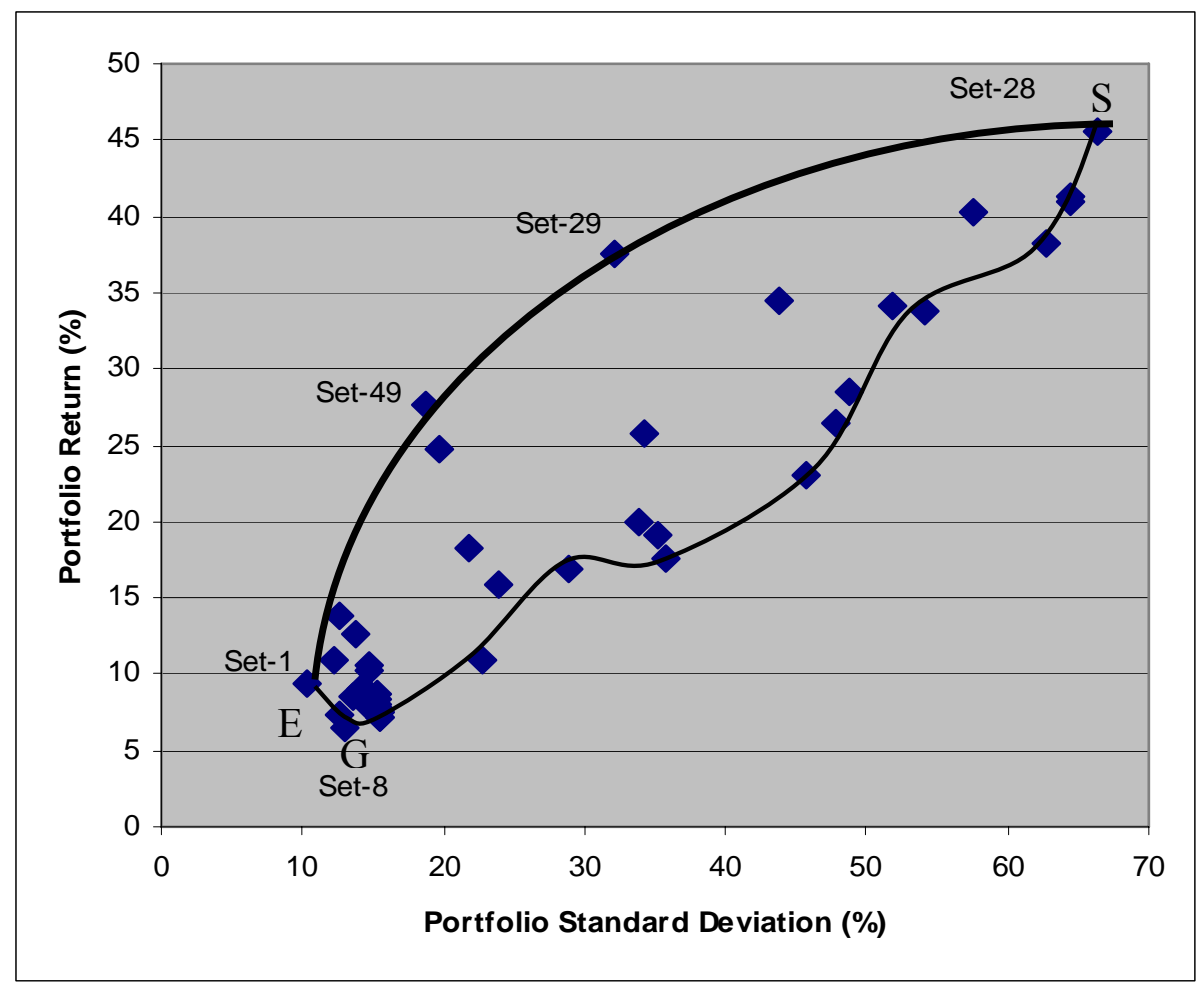

Fig. 3: Efficient Frontier of Two-stock Portfolios

Fig. 3 shows the risk and return pattern of fifty sets. In the figure point $\mathrm{E}$ is the minimum risk level (10.42 percent standard deviation) whereas the point $\mathrm{S}$ is maximum return ( 45.65 percent) as well as maximum risk level (66.35 percent standard deviation). The point $G$ is the minimum return level (6.57 percent). The area GES is the area of all feasible (attainable) portfolios. The boundary of the region identified as the curve ES dominates all other portfolios in the region. This area is known as the Markowitz efficient frontier and only the portfolios which lie in the efficient frontier are known as efficient portfolios. There are only four portfolios which lie in the efficient frontier, ES. They are: set- 
1, i.e., NFCL (31 percent investment) and BBCL (69 percent investment), set-28, i.e., AFCL (11.6 percent investment) and UNL (88.4 percent investment), Set-29, i.e., CIT (84.6 percent investment) and UNL (15.4 percent investment), and set-49, i.e. SCBNL (26.8 percent investment) and YFL (73.2 percent investment). The Set-1, Set-28, Set-29 and Set-49 offer 9.31 percent, 45.65 percent, 37.50 percent and 27.64 percent portfolio return respectively. Similarly, their risk in terms of standard deviation is 10.42 percent, 66.35 percent, 32.10 percent and 18.79 percent respectively. Hence, as per Markowitz, these four sets (portfolios) are efficient portfolios.

As per the risk and return preference of the investor, they will choose the optimal portfolio out of these four portfolios. Those investors with high appetite for risk will choose Set-28 and those with low appetite will choose Set-1.

\subsection{Ranking of Efficient Sets}

Applying the Markowitz two-asset model, the four portfolios have been found as efficient as they lie in the Markowitz efficient frontier. However, it is important to pick the best portfolio among these four efficient portfolios. In this regard, Sharpe and Treynor, among others, have developed their own 'measure' to rank the portfolios by evaluating the performance of portfolios.

The Sharpe ratio measures the amount of return from an investment portfolio for a given level of risk. It is obtained by dividing a measure of portfolio return volatility (the standard deviation of returns) into the excess returns generated by the portfolio over a risk-free rate of return. The higher the resulting number (index), the better is the portfolio performance. This ratio, also known as the rewardto-variability ratio, is used to rank the performance of investment funds. But Treynor uses systematic risk (beta) instead of total risk (standard deviation) to calculate the performance index. As depicted in Table 4 both measures rank the efficient portfolios in the same order. Set-49 (SCBNL \&YFL) ranks the first under both performance measures.

Table 4: Ranking of Two-stock Efficient Sets under Sharpe and Treynor Performance Measure

\begin{tabular}{lcccc}
$\begin{array}{l}\text { Two-Stock } \\
\text { Portfolios }\end{array}$ & $\begin{array}{c}\text { Ranking index under } \\
\text { Sharpe's Performance } \\
\text { Measure }\end{array}$ & Rank & $\begin{array}{l}\text { Ranking under } \\
\text { Treynor's Performance } \\
\text { Measure }\end{array}$ & Rank \\
\hline $\begin{array}{l}\text { Set-1 } \\
\text { (NFCL \& BBCL) }\end{array}$ & 0.406 & 4 & 13.734 & 4 \\
$\begin{array}{l}\text { Set-28 } \\
\text { (AFCL \& UNL) }\end{array}$ & 0.611 & 3 & 24.279 & 3 \\
$\begin{array}{l}\text { Set-29 } \\
\text { (CIT \& UNL) }\end{array}$ & 1.01 & 2 & 37.009 & 2 \\
$\begin{array}{l}\text { Set-49 } \\
\text { (SCBNL \& YFL) }\end{array}$ & 1201 & 1 & 48.621 & 1 \\
\hline
\end{tabular}

\subsection{Sharpe Portfolio Optimization Model}

Markowitz model is theoretically elegant and conceptually sound. However, its serious limitation is the volume of computational work it requires. Under Sharpe model the process of portfolio selection has been greatly simplified as a single number measures the desirability of including a stock in the optimal portfolio. Under this model, the stocks are ranked by excess return to beta ratio (from highest to lowest), and the ranking represents the desirability of any stock's inclusion in a portfolio. The number of stocks selected depends on a unique cutoff rate such that all stocks with higher ratios of $\left(R_{i}-R_{F}\right) / \beta_{i}$ will be included and all stocks with lower ratios excluded. We calculated the excess return-to-beta ratio for each stock under review, ranked them from highest to lowest order and included those stocks for which $\left(R_{i}-R_{F}\right) / \beta_{i}$ is greater than a particular cutoff point $\mathrm{C}^{*}$ in the optimum portfolio. 
Accordingly, the excess return-to-beta ratios for all sample stocks are computed and are ranked from highest to lowest order. They are presented in Annex 6. As per the ranking the stock of YFL has highest excess return-to-beta ratio (69.892) followed by stock of CIT (40.214), stock of HBL (35.017), stock of NICL (33.131) and stock of SCBNL (29.702). Hence, they are ranked one to five. The stock of SHL has the lowest excess return-to-beta (0.448).

Selecting the optimal portfolio involves the comparison of $\left(R_{i}-R_{F}\right) / \beta_{i}$ with cutoff rate $\left(\mathrm{C}^{*}\right)$. All securities whose excess return-to-beta ratios are above the cutoff rate are selected and whose ratios are below are rejected. Hence, the next step on the Sharpe model is to establish a cut-off rate $\left(\mathrm{C}^{*}\right)$. This has been computed and presented in Annex 7.

The highest $C_{i}$ value is 28.898 for SCBNL (Annex 7), hence, the cutoff rate $\left(\mathrm{C}^{*}\right)$ is 28.898 . There are only five stocks whose excess return-to-beta ratios are above the cutoff rate. Therefore, these five stocks form an optimal portfolio under this Sharpe model. It consists of stocks of YFL, CIT, HBL, NICL and SCBNL. The remaining 25 stocks are excluded from the portfolio as they have lower excess return-to-beta ratios than the cutoff rate.

\subsection{Arriving at the Optimal Portfolio}

Once we know which stocks are to be included in the optimum portfolios, we must find out the proportion of each security in the portfolio. The percentage invested in each security is:

Percentage invested in each security $\left(X_{i}^{0}\right)=\frac{Z_{i}}{\sum_{j=1}^{N} Z_{j}}$

Where,

$$
Z_{i}=\frac{\beta_{i}}{\sigma_{e i}^{2}}\left(\frac{R_{i}-R_{f}}{\beta_{i}}-C^{*}\right)
$$

The second expression determines the relative investment in each stock, and the first expression simply scales the weights on each security so that they sum to 1 (ensuring full investment). The residual variance on each stock $\sigma_{e i}^{2}$ plays an important role in determining how much to invest in each security. Applying the above formula, we have: $\mathrm{Z}_{\mathrm{YFL}}=0.0359, \mathrm{Z}_{\mathrm{CIT}}=0.0141, \mathrm{Z}_{\mathrm{HBL}}=0.0049, \mathrm{Z}_{\mathrm{NICL}}=$ 0.0026 and $Z_{\mathrm{SCBNL}}=0.0068$ and the sum of $Z$ value of 5 stocks is 0.0643 . Dividing each $Z_{i}$ by the sum of the $Z_{i}$, we would invest 55.81 percent in stock of YFL, 21.91 percent in stock of CIT, 7.66 percent in stock of HBL, 4.11 percent in stock of NICL and 10.52 percent in stock of SCBNL.

Though the calculation of weight for each stock for an optimal portfolio has been concluded, it is necessary to see the risk and return pattern of the optimal portfolio. The return of optimal portfolio is obtained multiplying the mean return of each stock by its proportion of investment, which is 30.19 percent. The variance of the portfolio is 390.43 , the standard deviation 19.78 percent and CV of the portfolio equal to 0.65 . If the $\mathrm{CV}$ of optimal portfolio is compared with the CVs of each single security, it is the lowest, indicating that the risk per unit of return is lowest in the portfolio formed by applying Sharpe model. The beta of the portfolio is also significantly lower $(0.5417)$ than that of the market.

These calculations show that an investor in Nepalese stock market can reduce risk in his/her investment by applying simple models of portfolio selection developed some five decades ago. 
Annex1: List of Sample Companies and Their Acronyms

\begin{tabular}{|c|c|}
\hline S.No. & Name \\
\hline & Banks \\
\hline 1 & Nabil Bank Ltd (NABIL) \\
\hline 2 & Nepal Investment Bank Ltd (NIBL) \\
\hline 3 & Standard Chartered Bank Nepal Ltd. (SCBNL) \\
\hline 4 & Himalayan Bank Ltd (HBL) \\
\hline 5 & Nepal SBI Bank Ltd (NSBIBL) \\
\hline 6 & Nepal Bangladesh Bank Ltd (NBBL) \\
\hline \multirow[t]{2}{*}{7} & Everest Bank Ltd (EBL) \\
\hline & Finance Companies \\
\hline 8 & Nepal Finance and Saving Co. Ltd (NFSCL) \\
\hline 9 & NIDC Capital Market Ltd (NCML) \\
\hline 10 & National Finance Co. Ltd (NFCL) \\
\hline 11 & Nepal Share Markets and and finance Ltd (NSMFL) \\
\hline 12 & Annapurna Finance Co Ltd (AFCL) \\
\hline 13 & Kathmandu Finance Ltd (KFL) \\
\hline 14 & Peoples Finance Ltd (PFL) \\
\hline 15 & Citizen Trust Ltd (CIT) \\
\hline 16 & Narayani finance Ltd (NFL) \\
\hline 17 & Ace Finance Ltd (AcFL) \\
\hline 18 & Yeti Finance Ltd (YFL) \\
\hline \multirow[t]{2}{*}{19} & Samjhana Finance Ltd (SFL) \\
\hline & Insurance Companies \\
\hline 20 & Nepal Insurance Co Ltd (NICL) \\
\hline 21 & National Life \& General Ins Co Ltd (NLGICL) \\
\hline 22 & Himalayan General Ins Co Ltd (HGICL) \\
\hline 23 & United Ins Co (Nepal) Ltd (UICL) \\
\hline 24 & Premier Insurance Co. Ltd (PICL) \\
\hline \multirow[t]{2}{*}{25} & Everest Insurance Co Ltd (EICL) \\
\hline & Manufacturing Companies \\
\hline 26 & Bottlers Nepal Ltd, Balaju (BNBL) \\
\hline 27 & Bottlers Nepal Ltd Tarai (BNTL) \\
\hline \multirow[t]{2}{*}{28} & Unliver Nepal Ltd (UNL) \\
\hline & Other Companies \\
\hline 29 & Soaltee Hotel Ltd (SHL) \\
\hline 30 & Bisal Bazar Co Ltd (BBCL) \\
\hline
\end{tabular}


Annex 2: Fifty Sets of Portfolios Having Least Correlation Coefficients

\begin{tabular}{|c|c|c|c|c|c|}
\hline S. $\mathbf{N}$. & Two Stocks & $\begin{array}{c}\text { Correlation } \\
\text { coefficient }\end{array}$ & S. $\mathbf{N}$. & Two Stocks & $\begin{array}{c}\text { Correlation } \\
\text { coefficient }\end{array}$ \\
\hline 1 & NFCL and BBCL & -0.437 & 26 & NFSCL and UNL & 0.103 \\
\hline 2 & NICL and BBCL & -0.310 & 27 & KFL and UNL & 0.106 \\
\hline 3 & KFL and BBCL & -0.240 & 28 & AFCL and UNL & 0.130 \\
\hline 4 & BNTL and BBCL & -0.214 & 29 & CIT and UNL & 0.148 \\
\hline 5 & SFL and BBCL & -0.187 & 30 & PICL and UNL & 0.162 \\
\hline 6 & NBBL and BBCL & -0.179 & 31 & $\mathrm{AcFL}$ and $\mathrm{BBCL}$ & 0.171 \\
\hline 7 & PICL and BBCL & -0.138 & 32 & UICL and BBCL & 0.174 \\
\hline 8 & SHL and BBCL & -0.137 & 33 & NSMFL and UNL & 0.180 \\
\hline 9 & $\mathrm{BNBL}$ and $\mathrm{BBCL}$ & -0.114 & 34 & $\begin{array}{l}\text { NSBIBL and } \\
\text { BBCL }\end{array}$ & 0.190 \\
\hline 10 & NFSCL and BBCL & -0.096 & 35 & $\begin{array}{l}\text { NFCL and } \\
\text { NLGICL }\end{array}$ & 0.198 \\
\hline 11 & UNL and BNBL & -0.093 & 36 & NFL and UNL & 0.219 \\
\hline 12 & CIT and BBCL & -0.077 & 37 & $\begin{array}{l}\text { NLGICL and } \\
\text { BNBL }\end{array}$ & 0.231 \\
\hline 13 & EICL and BBCL & -0.076 & 38 & PFL and UNL & 0.240 \\
\hline 14 & EICL and UNL & -0.067 & 39 & NABIL and BBCL & 0.241 \\
\hline 15 & NIBL and BBCL & -0.034 & 40 & NCML and UNL & 0.267 \\
\hline 16 & NFL and BBCL & -0.034 & 41 & SFL and UNL & 0.268 \\
\hline 17 & $\mathrm{HBL}$ and $\mathrm{BBCL}$ & -0.028 & 42 & PICL and NLGICL & 0.280 \\
\hline 18 & HGICL and BBCL & -0.014 & 43 & HGICL and UNL & 0.303 \\
\hline 19 & AFCL and BBCL & 0.018 & 44 & KFL and NLGICL & 0.308 \\
\hline 20 & NCML and BBCL & 0.039 & 45 & NSBIBL and UNL & 0.315 \\
\hline 21 & YFL and BBCL & 0.047 & 46 & EICL and NICL & 0.316 \\
\hline 22 & NSMFL and BBCL & 0.059 & 47 & $\begin{array}{l}\text { NFSCL and } \\
\text { NLGICL }\end{array}$ & 0.320 \\
\hline 23 & $\mathrm{EBL}$ and $\mathrm{BBCL}$ & 0.070 & 48 & YFL and NLGICL & 0.321 \\
\hline 24 & $\mathrm{UNL}$ and $\mathrm{BBCL}$ & 0.077 & 49 & SCBNL and YFL & 0.321 \\
\hline 25 & PFL and BBCL & 0.097 & 50 & SCBNL and BNBL & 0.322 \\
\hline
\end{tabular}


Application of Markowitz and Sharpe Models in Nepalese Stock Market

\section{Annex 3: Correlation Coefficient of 435 Pairs of Portfolio}

\begin{tabular}{|c|c|c|c|c|c|c|c|c|c|c|c|c|c|c|c|c|c|c|c|c|c|c|c|c|c|c|c|c|c|c|}
\hline $\begin{array}{l}\text { Listed } \\
\text { Cos. }\end{array}$ & $\frac{\overrightarrow{\bar{m}}}{\underline{z}}$ & $\overrightarrow{\mathrm{m}}$ & 总 & $\overrightarrow{\underline{m}}$ & $\begin{array}{l}\vec{m} \\
\vec{m} \\
\vec{z}\end{array}$ & $\overrightarrow{\underline{\tilde{m}}}$ & $\overrightarrow{\mathrm{m}}$ & 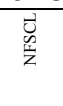 & $\sum_{Z}^{+}$ & $\begin{array}{l}\vec{U} \\
\text { 岀 }\end{array}$ & $\begin{array}{l}\overrightarrow{\mid} \\
\overrightarrow{\mid} \\
\vec{Z}\end{array}$ & 耑 & 臣 & $\overrightarrow{\underline{2}}$ & $E$ & $\overrightarrow{\mathrm{I}}$ & $\overrightarrow{⿱ 乛 龰}$ & $\vec{\Sigma}$ & 空 & $\overrightarrow{\vec{Z}}$ & $\begin{array}{l}\vec{U} \\
\vec{U} \\
\vec{z}\end{array}$ & $\begin{array}{l}\vec{U} \\
\overrightarrow{0}\end{array}$ & $\vec{J}$ & $\frac{\vec{U}}{2}$ & $\frac{\vec{J}}{\ddot{y}}$ & $\overrightarrow{\sum_{m}^{\prime}}$ & 党 & $\overrightarrow{\mathrm{Z}}$ & $\overrightarrow{F_{n}}$ & $\overline{\overrightarrow{\mathscr{D}}}$ \\
\hline NABIL & 1.000 & & & & & & & & & & & & & & & & & & & & & & & & & & & & & \\
\hline NIBL & 0.786 & 1.000 & & & & & & & & & & & & & & & & & & & & & & & & & & & & \\
\hline SCBNL & 0.919 & 0.781 & 1.000 & & & & & & & & & & & & & & & & & & & & & & & & & & & \\
\hline HBL & 0.871 & 0.611 & 0.763 & 1.000 & & & & & & & & & & & & & & & & & & & & & & & & & & \\
\hline NSBIB & 0.871 & 0.855 & 0.855 & 0.635 & 1.000 & & & & & & & & & & & & & & & & & & & & & & & & & \\
\hline NBBL & 0.847 & 0.788 & 0.721 & 0.874 & 0.731 & 1.000 & & & & & & & & & & & & & & & & & & & & & & & & \\
\hline EBL & 0.949 & 0.822 & 0.842 & 0.926 & 0.764 & 0.917 & 1.000 & & & & & & & & & & & & & & & & & & & & & & & \\
\hline NFSCL & 0.717 & 0.830 & 0.582 & 0.578 & 0.758 & 0.870 & 0.755 & 1.000 & & & & & & & & & & & & & & & & & & & & & & \\
\hline NCML & 0.842 & 0.817 & 0.759 & 0.666 & 0.884 & 0.891 & 0.795 & 0.934 & 1.000 & & & & & & & & & & & & & & & & & & & & & \\
\hline NFCL & 0.583 & 0.579 & 0.478 & 0.682 & 0.522 & 0.869 & 0.664 & 0.677 & 0.7331 & 1.000 & & & & & & & & & & & & & & & & & & & & \\
\hline NSMFL & 0.765 & 0.870 & 0.683 & 0.584 & 0.777 & 0.853 & 0.793 & 0.976 & 0.9300 & 0.619 & 1.000 & & & & & & & & & & & & & & & & & & & \\
\hline AFCL & 0.777 & 0.804 & 0.645 & 0.574 & 0.797 & 0.852 & 0.759 & 0.977 & 0.9650 & 0.653 & 0.9691 & 1.000 & & & & & & & & & & & & & & & & & & \\
\hline KFL & 0.691 & 0.827 & 0.590 & 0.586 & 0.754 & 0.885 & 0.725 & 0.974 & 0.9340 & 0.747 & 0.9360 & 0.949 & 1.000 & & & & & & & & & & & & & & & & & \\
\hline PFL & 0.912 & 0.857 & 0.773 & 0.776 & 0.879 & 0.865 & 0.905 & 0.889 & 0.8930 & 0.550 & 0.8910 & 0.894 & 0.846 & 1.000 & & & & & & & & & & & & & & & & \\
\hline CIT & 0.777 & 0.699 & 0.732 & 0.696 & 0.860 & 0.825 & 0.703 & 0.803 & 0.9120 & 0.674 & 0.7630 & 0.821 & 0.862 & 0.826 & 1.000 & & & & & & & & & & & & & & & \\
\hline NFL & 0.715 & 0.797 & 0.608 & 0.589 & 0.637 & 0.867 & 0.783 & 0.946 & 0.877 & 0.672 & 0.9690 & 0.941 & 0.915 & 0.820 & 0.683 & 1.000 & & & & & & & & & & & & & & \\
\hline ACFL & 0.833 & 0.611 & 0.899 & 0.794 & 0.712 & 0.768 & 0.776 & 0.507 & 0.7330 & 0.707 & 0.5770 & 0.575 & 0.557 & 0.612 & 0.718 & 0.565 & 1.000 & & & & & & & & & & & & & \\
\hline YFL & 0.456 & 0.393 & 0.321 & 0.536 & 0.332 & 0.712 & 0.574 & 0.676 & 0.6200 & 0.669 & 0.6690 & 0.624 & 0.596 & 0.516 & 0.437 & 0.709 & 0.4601 & 1.000 & & & & & & & & & & & & \\
\hline SFL & 0.777 & 0.845 & 0.683 & 0.644 & 0.794 & 0.914 & 0.785 & 0.942 & 0.9590 & 0.803 & 0.9240 & 0.953 & 0.973 & 0.849 & 0.860 & 0.917 & 0.6810 & 0.568 & 1.000 & & & & & & & & & & & \\
\hline NICL & 0.611 & 0.566 & 0.641 & 0.740 & 0.673 & 0.731 & 0.613 & 0.495 & 0.6410 & 0.747 & 0.4440 & 0.457 & 0.612 & 0.563 & 0.820 & 0.378 & 0.7430 & 0.339 & 0.627 & 1.000 & & & & & & & & & & \\
\hline NLGICL & 0.566 & 0.463 & 0.795 & 0.390 & 0.618 & 0.366 & 0.445 & 0.320 & 0.5230 & 0.198 & 0.4580 & 0.377 & 0.308 & 0.411 & 0.508 & 0.349 & 0.7320 & 0.321 & 0.356 & 0.439 & 1.000 & & & & & & & & & \\
\hline HGICL & 0.784 & 0.780 & 0.667 & 0.637 & 0.776 & 0.907 & 0.783 & 0.950 & 0.9740 & 0.789 & 0.9450 & 0.971 & 0.935 & 0.844 & 0.821 & 0.935 & 0.6890 & 0.734 & 0.961 & 0.549 & 0.4331 & 1.000 & & & & & & & & \\
\hline UICL & 0.830 & 0.803 & 0.808 & 0.745 & 0.832 & 0.883 & 0.838 & 0.855 & 0.9120 & 0.695 & 0.8880 & 0.842 & 0.825 & 0.851 & 0.823 & 0.822 & 0.7810 & 0.761 & 0.829 & 0.677 & 0.6920 & $0.894 \quad 1$ & 1.000 & & & & & & & \\
\hline PICL & 0.818 & 0.815 & 0.676 & 0.720 & 0.752 & 0.909 & 0.843 & 0.936 & 0.9090 & 0.673 & 0.9180 & 0.942 & 0.943 & 0.922 & 0.841 & 0.919 & 0.6000 & 0.528 & 0.948 & 0.554 & 0.2800 & 0.9020 & 0.788 & 1.000 & & & & & & \\
\hline EICL & 0.466 & 0.613 & 0.443 & 0.342 & 0.478 & 0.692 & 0.508 & 0.856 & 0.7820 & 0.551 & 0.8700 & 0.8460 & 0.867 & 0.615 & 0.657 & 0.905 & 0.4350 & 0.619 & 0.823 & 0.316 & 0.3650 & 0.8310 & 0.704 & 0.800 & 1.000 & & & & & \\
\hline BNBL & 0.459 & 0.454 & 0.322 & 0.473 & 0.398 & 0.738 & 0.532 & 0.839 & 0.7420 & 0.583 & 0.7990 & 0.8030 & 0.820 & 0.640 & 0.669 & 0.841 & 0.3670 & 0.784 & 0.743 & 0.362 & 0.2310 & 0.8040 & 0.712 & 0.781 & 0.899 & 1.000 & & & & \\
\hline BNTL & 0.741 & 0.737 & 0.677 & 0.816 & 0.584 & 0.905 & 0.858 & 0.671 & 0.7120 & 0.897 & 0.6890 & 0.6430 & 0.694 & 0.659 & 0.587 & 0.735 & 0.7950 & 0.676 & 0.771 & 0.679 & 0.3550 & 0.7650 & 0.777 & 0.697 & 0.506 & 0.494 & 1.000 & & & \\
\hline UNL & 0.532 & 0.366 & 0.559 & 0.615 & 0.315 & 0.479 & 0.584 & 0.103 & 0.2670 & 0.572 & 0.1800 & 0.1300 & 0.106 & 0.240 & 0.148 & 0.219 & 0.7200 & 0.360 & 0.268 & 0.439 & 0.3790 & 0.303 & 0.421 & 0.162 & -0.067 & -0.093 & 0.7621 & 1.000 & & \\
\hline SHL & 0.810 & 0.875 & 0.773 & 0.762 & 0.898 & 0.887 & 0.821 & 0.821 & 0.8850 & 0.770 & 0.7990 & 0.7860 & 0.854 & 0.855 & 0.888 & 0.709 & 0.7390 & 0.531 & 0.860 & 0.857 & 0.5030 & 0.8240 & 0.896 & 0.800 & 0.558 & 0.546 & 0.7930 & 0.418 & 1.000 & \\
\hline & & & $\mid 0.3$ & & & & & & & & & & & & & & & & & & & & & & & & 0 & & & \\
\hline
\end{tabular}


Annex 4: Computation of Weight of Each Stock in Two-Stock Portfolio, Portfolio Return, Portfolio Standard Deviation and Portfolio Variance

\begin{tabular}{|c|c|c|c|c|c|c|c|c|c|c|c|}
\hline Set & Two Assets Portfolios & $\sigma_{1}$ & $\sigma_{2}$ & $\rho_{12}$ & $\mathrm{w}_{1}$ & $\mathbf{w}_{2}$ & $\mathbf{E}\left(\mathbf{R}_{1}\right)$ & $\mathbf{E}\left(\mathbf{R}_{2}\right)$ & $\mathbf{R p}$ & $\sigma_{\mathrm{p}}$ & $\operatorname{Var}_{\mathrm{p}}$ \\
\hline 1 & NFCL and BBCL & 27.76 & 15.55 & -0.437 & 0.310 & 0.690 & 14.63 & 6.93 & 9.31 & 10.42 & 108.48 \\
\hline 2 & NICL and BBCL & 35.60 & 15.55 & -0.310 & 0.223 & 0.777 & 25.05 & 6.93 & 10.97 & 12.23 & 149.54 \\
\hline 3 & $\mathrm{KFL}$ and $\mathrm{BBCL}$ & 70.09 & 15.55 & -0.240 & 0.089 & 0.911 & 27.09 & 6.93 & 8.72 & 14.04 & 197.17 \\
\hline 4 & BNTL and BBCL & 63.11 & 15.55 & -0.214 & 0.097 & 0.903 & 29.08 & 6.93 & 9.08 & 14.07 & 197.85 \\
\hline 5 & SFL and BBCL & 56.04 & 15.55 & -0.187 & 0.109 & 0.891 & 21.59 & 6.93 & 8.53 & 14.06 & 197.62 \\
\hline 6 & NBBL and BBCL & 118.45 & 15.55 & -0.179 & 0.038 & 0.962 & 47.66 & 6.93 & 8.49 & 14.83 & 219.93 \\
\hline 7 & PICL and BBCL & 36.13 & 15.55 & -0.138 & 0.188 & 0.812 & 15.71 & 6.93 & 8.58 & 13.49 & 181.90 \\
\hline 8 & SHL and BBCL & 29.90 & 15.55 & -0.137 & 0.242 & 0.758 & 5.43 & 6.93 & 6.57 & 12.96 & 167.92 \\
\hline 9 & BNBL and BBCL & 25.34 & 15.55 & -0.114 & 0.294 & 0.706 & 8.18 & 6.93 & 7.30 & 12.55 & 157.38 \\
\hline 10 & NFSCL and BBCL & 140.36 & 15.55 & -0.096 & 0.022 & 0.978 & 41.92 & 6.93 & 7.71 & 15.22 & 231.80 \\
\hline 11 & UNL and BNBL & 69.18 & 15.55 & -0.093 & 0.065 & 0.935 & 40.85 & 8.18 & 10.32 & 14.81 & 219.45 \\
\hline 12 & $\mathrm{CIT}$ and $\mathrm{BBCL}$ & 33.98 & 15.55 & -0.077 & 0.191 & 0.809 & 36.89 & 6.93 & 12.66 & 13.70 & 187.80 \\
\hline 13 & EICL and BBCL & 59.97 & 15.55 & -0.076 & 0.079 & 0.921 & 29.45 & 6.93 & 8.70 & 14.74 & 217.24 \\
\hline 14 & EICL and UNL & 59.97 & 69.18 & -0.067 & 0.567 & 0.433 & 29.45 & 40.85 & 34.39 & 43.78 & 1917.01 \\
\hline 15 & NFL and BBCL & 79.66 & 15.55 & -0.034 & 0.043 & 0.957 & 39.41 & 6.93 & 8.31 & 15.16 & 229.72 \\
\hline 16 & NIBL and BBCL & 41.93 & 15.55 & -0.034 & 0.129 & 0.871 & 23.25 & 6.93 & 9.04 & 14.41 & 207.72 \\
\hline 17 & HBL and BBCL & 47.28 & 15.55 & -0.028 & 0.104 & 0.896 & 42.04 & 6.93 & 10.59 & 14.64 & 214.46 \\
\hline 18 & HGICL and BBCL & 49.89 & 15.55 & -0.014 & 0.092 & 0.908 & 16.27 & 6.93 & 7.79 & 14.79 & 218.61 \\
\hline 19 & $\mathrm{AFCL}$ and $\mathrm{BBCL}$ & 163.78 & 15.55 & 0.018 & 0.007 & 0.993 & 82.34 & 6.93 & 7.48 & 15.50 & 240.38 \\
\hline 20 & NCML and BBCL & 108.02 & 15.55 & 0.039 & 0.015 & 0.985 & 43.00 & 6.93 & 7.47 & 15.46 & 239.16 \\
\hline 21 & $\mathrm{YFL}$ and $\mathrm{BBCL}$ & 20.35 & 15.55 & 0.047 & 0.362 & 0.638 & 25.90 & 6.93 & 13.80 & 12.63 & 159.56 \\
\hline 22 & NSMFL and BBCL & 108.98 & 15.55 & 0.059 & 0.012 & 0.988 & 30.26 & 6.93 & 7.21 & 15.50 & 240.11 \\
\hline 23 & EBL and $\mathrm{BBCL}$ & 72.74 & 15.55 & 0.070 & 0.030 & 0.970 & 62.72 & 6.93 & 8.62 & 15.39 & 236.88 \\
\hline 24 & UNL and BBCL & 69.18 & 15.55 & 0.077 & 0.033 & 0.967 & 40.85 & 6.93 & 8.04 & 15.38 & 236.60 \\
\hline 25 & PFL and BBCL & 55.07 & 15.55 & 0.097 & 0.051 & 0.949 & 18.49 & 6.93 & 7.52 & 15.29 & 233.70 \\
\hline 26 & NFSCL and UNL & 140.36 & 69.18 & 0.103 & 0.168 & 0.832 & 41.92 & 40.85 & 41.03 & 64.41 & 4148.52 \\
\hline 27 & KFL and UNL & 70.09 & 69.18 & 0.106 & 0.493 & 0.507 & 27.09 & 40.85 & 34.07 & 51.78 & 2681.14 \\
\hline 28 & AFCL and UNL & 163.78 & 69.18 & 0.130 & 0.116 & 0.884 & 82.34 & 40.85 & 45.65 & 66.35 & 4402.97 \\
\hline 29 & CIT and UNL & 33.98 & 69.18 & 0.148 & 0.846 & 0.154 & 36.89 & 40.85 & 37.50 & 32.10 & 1030.55 \\
\hline 30 & PICL and UNL & 36.13 & 69.18 & 0.162 & 0.830 & 0.170 & 15.71 & 40.85 & 20.00 & 33.94 & 1151.85 \\
\hline 31 & AcFL and $\mathrm{BBCL}$ & 45.36 & 15.55 & 0.171 & 0.059 & 0.941 & 30.42 & 6.93 & 8.31 & 15.32 & 234.67 \\
\hline 32 & UICL and BBCL & 36.63 & 15.55 & 0.174 & 0.103 & 0.897 & 15.16 & 6.93 & 7.78 & 15.07 & 227.10 \\
\hline 33 & NSMFL and UNL & 108.98 & 69.18 & 0.180 & 0.246 & 0.754 & 30.26 & 40.85 & 38.25 & 62.79 & 3943.00 \\
\hline 34 & NSBIBL and BBCL & 64.75 & 15.55 & 0.190 & 0.012 & 0.988 & 27.86 & 6.93 & 7.19 & 15.53 & 241.17 \\
\hline 35 & NFCL and NLGICL & 27.76 & 35.93 & 0.198 & 0.656 & 0.344 & 14.63 & 18.03 & 15.80 & 23.95 & 573.52 \\
\hline 36 & NFL and UNL & 79.66 & 69.18 & 0.219 & 0.411 & 0.589 & 39.41 & 40.85 & 40.26 & 57.59 & 3316.56 \\
\hline 37 & NLGICL and BNBL & 35.93 & 25.34 & 0.231 & 0.285 & 0.715 & 18.03 & 8.18 & 10.99 & 22.78 & 518.84 \\
\hline 38 & PFL and UNL & 55.07 & 69.18 & 0.240 & 0.646 & 0.354 & 18.49 & 40.85 & 26.40 & 47.79 & 2283.53 \\
\hline 39 & NABIL and BBCL & 50.44 & 15.55 & 0.241 & 0.022 & 0.978 & 44.86 & 6.93 & 7.76 & 15.51 & 240.65 \\
\hline 40 & NCML and UNL & 108.02 & 69.18 & 0.267 & 0.224 & 0.776 & 43.00 & 40.85 & 41.33 & 64.51 & 4161.05 \\
\hline 41 & SFL and UNL & 56.04 & 69.18 & 0.268 & 0.641 & 0.359 & 21.59 & 40.85 & 28.51 & 48.84 & 2385.36 \\
\hline 42 & PICL and NLGICL & 36.13 & 35.93 & 0.280 & 0.496 & 0.504 & 15.71 & 18.03 & 16.88 & 28.82 & 830.80 \\
\hline 43 & HGICL and UNL & 49.89 & 69.18 & 0.303 & 0.722 & 0.278 & 16.27 & 40.85 & 23.11 & 45.69 & 2087.16 \\
\hline 44 & KFL and NLGICL & 70.09 & 35.93 & 0.308 & 0.111 & 0.889 & 27.09 & 18.03 & 19.03 & 35.13 & 1233.88 \\
\hline 45 & NSBIBL and UNL & 64.75 & 69.18 & 0.315 & 0.548 & 0.452 & 27.86 & 40.85 & 33.73 & 54.18 & 2935.82 \\
\hline 46 & EICL and NICL & 59.97 & 35.60 & 0.316 & 0.169 & 0.831 & 29.45 & 25.05 & 25.79 & 34.17 & 1167.40 \\
\hline 47 & NFSCL and NLGICL & 140.36 & 35.93 & 0.320 & -0.018 & 1.018 & 41.92 & 18.03 & 17.60 & 35.85 & 1285.10 \\
\hline 48 & YFL and NLGICL & 20.35 & 35.93 & 0.321 & 0.855 & 0.145 & 25.90 & 18.03 & 24.76 & 19.70 & 388.07 \\
\hline 49 & SCBNL and YFL & 28.44 & 20.35 & 0.321 & 0.268 & 0.732 & 32.37 & 25.90 & 27.64 & 18.79 & 352.88 \\
\hline 50 & SCBNL and BNBL & 28.44 & 25.34 & 0.322 & 0.416 & 0.584 & 32.37 & 8.18 & 18.23 & 21.72 & 471 \\
\hline
\end{tabular}




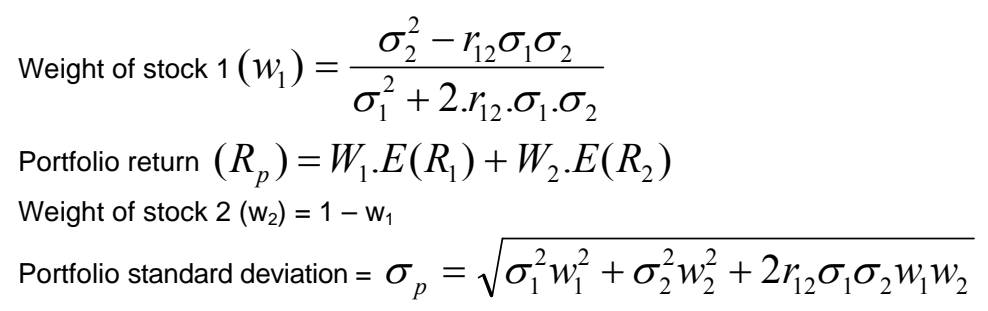

\section{Annex 5.1: Ranking of Two-stock Efficient Sets under Sharpe Performance Measure}

\begin{tabular}{|c|c|c|c|c|c|}
\hline $\begin{array}{l}\text { Two-Stock } \\
\text { Portfolios } \\
\end{array}$ & $\begin{array}{c}\text { Portfolio return } \\
\left(\mathrm{R}_{\mathrm{p}}\right)\end{array}$ & $\begin{array}{l}\text { Portfolio std. } \\
\text { deviation }\left(\sigma_{p}\right)\end{array}$ & $\begin{array}{c}\text { Risk-free rate } \\
\left(\mathrm{R}_{\mathrm{f}}\right)\end{array}$ & $S_{p}=\frac{R_{p}-R_{f}}{\sigma_{p}}$ & Rank \\
\hline Set-1 (NFCL \& BBCL) & $9.31 \%$ & $10.42 \%$ & $5.08 \%$ & $\frac{9.31-5.08}{10.42}=0.406$ & 4 \\
\hline Set-28 (AFCL \& UNL) & 45.65 & 66.35 & 5.08 & $\frac{45.65-5.08}{66.35}=0.611$ & 3 \\
\hline Set-29 (CIT \& UNL) & 37.50 & 32.10 & 5.08 & $\frac{37.50-5.08}{32.10}=1.01$ & 2 \\
\hline Set-49 (SCBNL \& YFL) & 27.64 & 18.79 & 5.08 & $\frac{27.64-5.08}{18.79}=1.201$ & 1 \\
\hline
\end{tabular}

Annex 5.2: Ranking of Two-stock Efficient Sets under Treynor Performance Measure

\begin{tabular}{|c|c|c|c|c|c|}
\hline $\begin{array}{l}\text { Two-Stock } \\
\text { Portfolios }\end{array}$ & $\begin{array}{l}\text { Portfolio return } \\
\qquad\left(\mathrm{R}_{\mathrm{p}}\right)\end{array}$ & Portfolio beta $\left(\beta_{\mathrm{p}}\right)^{1}$ & $\begin{array}{l}\text { Risk-free } \\
\text { rate }\left(\mathrm{R}_{\mathrm{f}}\right)\end{array}$ & $T_{p}=\frac{R_{p}-R_{f}}{\beta_{p}}$ & Rank \\
\hline Set-1 (NFCL \& BBCL) & $9.31 \%$ & $0.308^{2}$ & $5.08 \%$ & $\frac{9.31-5.08}{0.308}=13.734$ & 4 \\
\hline Set-28 (AFCL \& UNL) & 45.65 & $1.671^{3}$ & 5.08 & $\frac{45.65-5.08}{1.671}=24.279$ & 3 \\
\hline Set-29 (CIT \& UNL) & 37.50 & $0.876^{4}$ & 5.08 & $\frac{37.50-5.08}{0.876}=37.009$ & 2 \\
\hline Set-49 (SCBNL \& YFL) & 27.64 & $0.464^{5}$ & 5.08 & $\frac{27.64-5.08}{0.464}=48.621$ & 1 \\
\hline
\end{tabular}

Annex 6: Computation of Excess Return to Beta and Ranking of Securities

\begin{tabular}{|c|c|c|c|c|c|c|c|}
\hline (1) & (2) & (3) & (4) & (5) & (6) & (7) & (8) \\
\hline \multirow[t]{2}{*}{ S.N. } & \multirow[t]{2}{*}{ Securities, $i$} & $\begin{array}{l}\text { Expected } \\
\text { Return }\end{array}$ & $\begin{array}{l}\text { Excess } \\
\text { Return }\end{array}$ & $\begin{array}{c}\text { Beta } \\
\text { Coefficient }\end{array}$ & $\begin{array}{l}\text { Unsystematic } \\
\text { Risk }\end{array}$ & $\begin{array}{c}\text { Excess Return to } \\
\text { Beta }\end{array}$ & \multirow[t]{2}{*}{ Rank } \\
\hline & & $\boldsymbol{R}_{i}$ & $\boldsymbol{R}_{i}-\boldsymbol{R}_{f}$ & $\boldsymbol{\beta}_{i}$ & $\sigma_{e i}{ }^{2}$ & $\left(\boldsymbol{R}_{i}-\boldsymbol{R}_{F}\right) / \boldsymbol{\beta}_{i}$ & \\
\hline 1 & NABIL & 44.86 & 39.78 & 1.588 & 453.93 & 25.056 & 9 \\
\hline 2 & NIBL & 23.25 & 18.17 & 1.175 & 613.33 & 15.468 & 15 \\
\hline 3 & SCBNL & 32.37 & 27.29 & 0.919 & 109.11 & 29.702 & 5 \\
\hline 4 & HBL & 42.04 & 36.96 & 1.055 & 1311.38 & 35.017 & 3 \\
\hline 5 & NSBIBL & 27.86 & 22.78 & 2.008 & 846.93 & 11.343 & 23 \\
\hline 6 & NBBL & 47.66 & 42.58 & 2.868 & 7208.80 & 14.848 & 16 \\
\hline
\end{tabular}

\footnotetext{
${ }^{1}$ Portfolio Beta is computed by using this formula: (weight of stock- $1 \times$ Beta of stock- $1+$ weight of stock- $2 \times$ Beta of stock-2)

${ }^{2} 0.31 \times 0.469+0.69 \times 0.235=0.308$

${ }^{3} 0.116 \times 4.193+0.884 \times 1.34=1.671$

${ }^{4} 0.846 \times 0.791+0.154 \times 1.34=0.876$

${ }^{5} 0.268 \times 0.919+0.732 \times 0.298=0.464$
} 
The Journal of Nepalese Business Studies

Appendix 6 (Continued)

\begin{tabular}{|c|c|c|c|c|c|c|c|}
\hline 7 & EBL & 62.72 & 57.64 & 2.046 & 1818.18 & 28.166 & 6 \\
\hline 8 & NFSCL & 41.92 & 36.84 & 3.216 & 11123.37 & 11.454 & 22 \\
\hline 9 & NCML & 43.00 & 37.92 & 3.059 & 3907.13 & 12.396 & 20 \\
\hline 10 & NFCL & 14.63 & 9.55 & 0.469 & 588.59 & 20.367 & 10 \\
\hline 11 & NSMFL & 30.26 & 25.18 & 2.865 & 5068.18 & 8.787 & 27 \\
\hline 12 & AFCL & 82.34 & 77.26 & 4.193 & 12240.61 & 18.426 & 13 \\
\hline 13 & KFL & 27.09 & 22.01 & 1.498 & 3051.58 & 14.697 & 17 \\
\hline 14 & PFL & 18.49 & 13.41 & 1.514 & 1130.81 & 8.856 & 26 \\
\hline 15 & CIT & 36.89 & 31.81 & 0.791 & 635.60 & 40.214 & 2 \\
\hline 16 & NFL & 39.41 & 34.33 & 1.852 & 3501.02 & 18.537 & 12 \\
\hline 17 & AcFL & 30.42 & 25.34 & 1.295 & 666.29 & 19.567 & 11 \\
\hline 18 & YFL & 25.90 & 20.82 & 0.298 & 340.44 & 69.892 & 1 \\
\hline 19 & SFL & 21.59 & 16.51 & 1.397 & 1522.99 & 11.823 & 21 \\
\hline 20 & NICL & 25.05 & 19.97 & 0.603 & 966.18 & 33.131 & 4 \\
\hline 21 & NLGICL & 18.03 & 12.95 & 0.937 & 563.53 & 13.824 & 18 \\
\hline 22 & HGICL & 16.27 & 11.19 & 1.315 & 1055.13 & 8.508 & 28 \\
\hline 23 & UICL & 15.16 & 10.08 & 1.056 & 416.66 & 9.544 & 25 \\
\hline 24 & PICL & 15.71 & 10.63 & 0.833 & 729.15 & 12.758 & 19 \\
\hline 25 & EICL & 29.45 & 24.37 & 0.963 & 2826.37 & 25.295 & 8 \\
\hline 26 & BNBL & 8.18 & 3.10 & 0.291 & 571.64 & 10.636 & 24 \\
\hline 27 & BNTL & 29.08 & 24.00 & 1.461 & 2212.25 & 16.427 & 14 \\
\hline 28 & UNL & 40.85 & 35.77 & 1.340 & 3298.21 & 26.699 & 7 \\
\hline 29 & SHL & 5.43 & 0.35 & 0.785 & 382.96 & 0.448 & 30 \\
\hline 30 & BBCL & 6.93 & 1.85 & 0.235 & 196.25 & 7.888 & 29 \\
\hline
\end{tabular}

*Risk-free rate is 5.08 percent.

Annex 7: Calculations of Cut-off Rates

\begin{tabular}{|c|l|r|r|r|r|r|r|}
\hline$(1)$ & \multicolumn{1}{|c|}{$(2)$} & $(3)$ & $(4)$ & $(5)$ & $(6)$ & $(7)$ & $(8)$ \\
\hline Rank & \multicolumn{1}{|c|}{$\begin{array}{c}\text { Security } \\
\end{array}$} & $\frac{\left(R_{i}-R_{f}\right)}{\beta_{i}}$ & $\frac{\left(R_{i}-R_{f}\right) \beta_{i}}{\sigma_{e i}^{2}}$ & $\frac{\beta_{i}{ }^{2}}{\sigma_{e i}^{2}}$ & $\sum_{i=1}^{j} \frac{\left(R_{i}-R_{f}\right) \beta_{i}}{\sigma_{e i}^{2}}$ & $\sum_{i=1} \frac{\beta_{i}{ }^{2}}{\sigma_{i}^{2}}$ & $\mathbf{C}_{\mathbf{i}}$ \\
\hline 1 & YFL & 69.892 & 0.01822 & 0.00026 & 0.01822 & 0.00026 & 12.424 \\
\hline 2 & CIT & 40.214 & 0.03958 & 0.00098 & 0.05780 & 0.00124 & 23.585 \\
\hline 3 & HBL & 35.017 & 0.02974 & 0.00085 & 0.08754 & 0.00209 & 26.527 \\
\hline 4 & NICL & 33.131 & 0.01246 & 0.00038 & 0.10000 & 0.00247 & 27.203 \\
\hline 5 & SCBNL & 29.702 & 0.22980 & 0.00774 & 0.32980 & 0.01021 & 28.898 \\
\hline 6 & EBL & 28.166 & 0.06487 & 0.00230 & 0.39467 & 0.01251 & 28.775 \\
\hline 7 & UNL & 26.699 & 0.01453 & 0.00054 & 0.40919 & 0.01305 & 28.696 \\
\hline 8 & EICL & 25.295 & 0.00830 & 0.00033 & 0.41750 & 0.01338 & 28.620 \\
\hline 9 & NABIL & 25.056 & 0.13912 & 0.00555 & 0.55662 & 0.01893 & 27.637 \\
\hline 10 & NFCL & 20.367 & 0.00761 & 0.00037 & 0.56423 & 0.01931 & 27.505 \\
\hline 11 & AcFL & 19.567 & 0.04927 & 0.00252 & 0.61349 & 0.02183 & 26.637 \\
\hline 12 & NFL & 18.537 & 0.01816 & 0.00098 & 0.63166 & 0.02281 & 26.307 \\
\hline 13 & AFCL & 18.426 & 0.02647 & 0.00144 & 0.65813 & 0.02424 & 25.862 \\
\hline 14 & BNTL & 16.427 & 0.01585 & 0.00096 & 0.67398 & 0.02521 & 25.517 \\
\hline 15 & NIBL & 15.468 & 0.03482 & 0.00225 & 0.70879 & 0.02746 & 24.728 \\
\hline
\end{tabular}


Application of Markowitz and Sharpe Models in Nepalese Stock Market

\begin{tabular}{|c|c|c|c|c|c|c|c|}
\hline 16 & NBBL & 14.848 & 0.01694 & 0.00114 & 0.72573 & 0.02860 & 24.350 \\
\hline 17 & KFL & 14.697 & 0.01080 & 0.00074 & 0.73654 & 0.02933 & 24.117 \\
\hline 18 & NLGICL & 13.824 & 0.02153 & 0.00156 & 0.75807 & 0.03089 & 23.618 \\
\hline 19 & PICL & 12.758 & 0.01215 & 0.00095 & 0.77022 & 0.03184 & 23.305 \\
\hline 20 & NCML & 12.396 & 0.02969 & 0.00240 & 0.79991 & 0.03424 & 22.568 \\
\hline 21 & SFL & 11.823 & 0.01514 & 0.00128 & 0.81506 & 0.03552 & 22.193 \\
\hline 22 & NFSCL & 11.454 & 0.01065 & 0.00093 & 0.82571 & 0.03645 & 21.928 \\
\hline 23 & NSBIBL & 11.343 & 0.05402 & 0.00476 & 0.87973 & 0.04121 & 20.739 \\
\hline 24 & BNBL & 10.636 & 0.00158 & 0.00015 & 0.88131 & 0.04136 & 20.704 \\
\hline 25 & UICL & 9.544 & 0.02556 & 0.00268 & 0.90687 & 0.04404 & 20.044 \\
\hline 26 & PFL & 8.856 & 0.01796 & 0.00203 & 0.92483 & 0.04607 & 19.563 \\
\hline 27 & NSMFL & 8.787 & 0.01423 & 0.00162 & 0.93906 & 0.04769 & 19.206 \\
\hline 28 & HGICL & 8.508 & 0.01394 & 0.00164 & 0.95300 & 0.04933 & 18.860 \\
\hline 29 & BBCL & 7.888 & 0.00221 & 0.00028 & 0.95521 & 0.04961 & 18.799 \\
\hline 30 & SHL & 0.448 & 0.00072 & 0.00161 & 0.95593 & 0.05121 & 18.236 \\
\hline
\end{tabular}

- $\quad$ Variance of NEPSE return $\left(\operatorname{Var}_{N E P S E}=829.33\right)$

\section{REFERENCES}

Adhikari, Deepak. 2002. "Risk and Return on Common Stock Investment." M.B.S. diss. T.U.

Bhatta, Dipesh. 2003. "Portfolio Management of Listed Finance Companies in Nepal." M.B.S. diss., T.U.

Bhatta, Gopal P. 1995. "Assessment of Performance of Listed Companies in Nepal." M.B.S. diss., T.U.

Fischer, Donald E., and Ronald J. Jordan. 2000. Security Analysis and Portfolio Management. New Delhi: Prentice Hall of India Pvt. Ltd.

Francis, Jack C. 1998. Investments: Analysis and Management. International ed. New York: McGraw Hill Inc.

Goetzmann, William N. 1999. An Introduction of Investment Theory. Yale: Yale School of Management.

Koirala, Parashar, and Pushkar Bajracharya. 2004. Nepalese Capital Market: Issues and Challenges. Economic Review $16: 1-16$.

Koirala, Sujan. 2007. "Formation of Optimal Portfolios from the Common Stocks Listed in Nepal Stock Exchange Limited." M.B.S. diss., T.U.

Markowitz, Harry M. 1952. Portfolio Selection. Journal of Finance 7: 77-91.

Markowitz, Harry M. 1956. The Optimisation of a Quadratic Function Subject to Linear Constraints. Naval Research Logistics Quarterly 8: 111-133.

Markowitz, Harry M. 1959. Portfolio Selection: Efficient Diversification of Investment. New York: John Wiley and Sons.

Joshi, Roopak. 2002. "Investor's Problems in Choice of Optimum Portfolio of Stocks in Nepal Stock Exchange." M.B.S. diss., T.U.

Khadka, Nayan Bahadur. 2006. "Stock Market and Portfolio Analysis of Banking and Manufacturing and Processing Companies." M.B.S. diss., T.U.

Pantha, Ganesh Prasad. 2005. "Stock Market and Portfolio Analysis." M.B.S. diss., T.U.

Poudyal, Khem N. 2002. "Formation of Optimum Investment Portfolio in Grade "A" Companies listed in Nepal Stock Exchange." M.B.S. diss., T.U.

Sharpe, William F. 1963. A Simplified Model for Portfolio Analysis. Management Science 9 : 227-293.

-- -- -. 1964. Capital Asset prices: A Theory of Market Equilibrium under Conditions of Risk. Journal of Finance 19: 425-442.

Sharpe, William F., Gordan J. Alexander, and Jeffery V. Bailey. 1995. Investments. New Delhi: Prentice Hall of India Pvt. Ltd.

Shrestha, Anurodh. 2004. "Portfolio Management in Nepal: A Case Study of Listed Commercial Banks in NEPSE." M.B.S. diss., T.U.

Shrestha, Haripati Lal. 2004. "Optimum Portfolio Investment in NEPSE." M.B.S. diss., T.U.

Sapkota, J. B. 2000. "Risk \& Return Analysis in Common Stock Investment." M.B.S. diss., T.U.

Shrestha, Mita. 2006. "Portfolio Analysis of Joint Venture Banks of Nepal (with special reference to Nepal Bangladesh Bank Ltd., Nepal SBI Bank Ltd. and Everest Bank Ltd." M.B.S. diss., T.U. 